\title{
Designers do Movimento Maker no Combate ao COVID-19: análise de iniciativas em Pernambuco
}

Thaciana Caroline Belarmino Ferreira;

Kaio Mircleano Pereira de Lima;

Kátia Medeiros Araújo

resumo:

A pandemia do novo coronavírus teve um grande impacto em diversas áreas da indústria. Uma das mais afetadas foi o setor responsável pela fabricação e distribuição de EPI's, elementos essenciais para diminuir a propagação do vírus. Este trabalho aborda produções de designers, ativistas, em colaboração com entidades associadas ao ideário do movimento maker. Como ferramenta teórica da análise foram utilizados os conceitos de caixa preta, e fatores humanos e não humanos nas transformações de ideias científicas em materialidade, bem como as reflexões de Latour sobre arregimentação de aliados e remanejamento de interesses na produção tecnológica. Serviram de objeto empírico registros de internet relativos à atuação de laboratórios de fabricação digital na produção desses itens essenciais no combate ao vírus. Da análise concluímos que as propostas que se voltaram para uma perspectiva coletivista e inclusiva, foram fruto de interesses formados em processos colaborativos.

palavras-chave:

Movimento Maker, Design; Fabricação Digital; COVID-19 


\section{Introdução}

Neste trabalho, propomos uma reflexão sobre a atuação de designers, ativistas e entidades associados ao ideário do movimento maker, assim como de algumas instituições que têm tido repercussão por suas iniciativas produtivas no contexto da crise sanitária mundial causada pelo Covid-19.

Serviram de objeto de análise um conjunto de documentos digitais, informativos em termos de conteúdos de projetos e relatos orais de seus protagonistas centrais - makers e designers que atuaram no desenvolvimento dos artefatos voltados a minimizar os efeitos danosos da pandemia do ponto de vista social.

Na construção da reflexão, nos valemos das considerações teóricas de Bruno Latour em suas problematizações acerca das relações que envolvem cientistas e tecnólogos, além de poderes econômicos e institucionais em torno da produção dos artefatos tecnológicos e produtos científicos palpáveis - os quais o autor denomina de caixas pretas.

Diante deste contexto é que situamos a questão objetivada na presente comunicação: o que significa a decisão e o empenhar esforços para a produção de artefatos simples e de valor econômico unitário irrisório, voltados à coletividade, para a qual é necessário mobilizar apoio econômico e simbólico através de redes sociais? Enfim, o que passou a significar o produzir máscaras e Face Shields no contexto das pretensões que tem o design no mundo atual?

A nosso ver, a pandemia parece recuperar um aspecto que, apesar de constar como elemento central na visão que conhecemos como vanguarda histórica deste campo profissional - sua dimensão social, exemplificada, por exemplo, pela ideia de atendimento de necessidades sociais, nas perspectivas de autores como Dorfles e Lobach, ou mesmo no conceito de design colaborativo, empregado por Manzini - encontrava-se bastante ofuscada em muitas das suas práticas contemporâneas.

\section{Crise Sanitária, Artefatos e Corolários Profissionais}

A pandemia causada pelo novo coronavírus (SARS-Cov-2) tem se apresentado como um dos maiores desafios sanitários da história recente. Atualmente no Brasil, segundo os dados oficiais do Ministério da Saúde no dia 14 de agosto, foram contabilizados mais de 3 milhões de casos e 107 mil óbitos. As lacunas nas informações sobre essa nova doença vêm desafiando a comunidade científica, em uma corrida contra o tempo, para estudar seus efeitos e buscar estratégias de combate para o enfrentamento desta crise sem precedentes.

Os coronavírus constituem uma grande família de vírus comuns que infectam diferentes espécies de animais e raramente pessoas. Através de uma mutação genética, em dezembro de 2019 houve a transmissão de um novo coronavírus (SARS-CoV-2) em Wuhan, na China, que causou a pandemia do COVID-19 quando a doença foi transmitida de pessoa a pessoa atingindo todos os continentes em escala global (MINISTÉRIO DA SAÚDE, 2020). Segundo a Organização Mundial da Saúde (2020), cerca de $80 \%$ dos pacientes com COVID-19 podem ser assintomáticos ou apresentar poucos sintomas o que dificulta o diagnóstico e controle desse tipo de infectados. A doença causa sintomas que variam dos mais parecidos com um resfriado até uma pneumonia severa. A imprevisibilidade de como o vírus vai reagir no organismo de cada pessoa aumenta o perigo de contrair a doença, uma vez que não há certezas sobre como e quais sintomas se manisfestarão. O vírus se espalha através de gotículas de saliva, tosses, espirros e contato com superfícies contaminadas. Sendo assim, a principal forma de prevenção, além do isolamento social, consiste em lavar-se as mãos com água e sabão ou higienizá-las com álcool em gel 70\% (MINISTÉRIO DA SAÚDE, 2020).

$\mathrm{O}$ mundo inteiro foi posto de quarentena e além de estarmos reclusos em nossas residências, o cotidiano mudou em diversos aspectos, dentre eles o surgimento de um novo artefato essencial: as máscaras de proteção. A pandemia também evidenciou desigualdades sociais alarmantes ao se tratar de uma crise sanitária em escala mundial. Com relação ao Brasil, Werneck e Carvalho (2020) destacam que a desigualdade social representa um grande desafio, tendo em vista que uma parcela da população vive aglomerada e em condições habitacionais precárias, muitas vezes sem acesso a saneamento básico ou água encanada limpa. Essa falta de acesso à água encanada (sem contar a falta de sistema de saneamento adequado) impossibilita considerável parcela de realizar um dos principais métodos de prevenção contra a contaminação, a higienização frequente das mãos. 
Um fator que deve ser observado é que, como apresenta Negri et al (2020), a pandemia atual se desenvolveu num cenário com maior integração entre países e pessoas. Toda essa interação trouxe uma maior dificuldade na tentativa de conter o vírus, que rapidamente se espalhou por todos os continentes. Em contrapartida, a intensificação do uso da internet e das mídias sociais permitiu uma rede de colaboração em busca de conhecimento sobre o novo vírus. Isso foi o que possibilitou que especialistas das mais diversas áreas de saberes em diferentes partes do mundo unissem esforços na tentativa de minimizar os danos causados pela nova doença. Além do maior compartilhar de conhecimento, quando se compara o quadro atual com o contexto do surto de H1N1 ocorrido há dez anos, a tecnologia e o mapeamento genético agilizaram o processo de estudo e desenvolvimento de diagnóstico para o coronavírus $(\mathrm{G} 1,2020)$.

Além de pesquisadores e profissionais do campo da saúde, profissionais de outras diversas áreas têm se mobilizado na busca por ferramentas para o combate à pandemia do COVID-19. A Organização Mundial de Saúde - OMS tem mapeado a produção de pesquisas, promovendo o encontro de cientistas de todo mundo para compartilhar conhecimento sobre o vírus e definir as perguntas que precisam ser respondidas com urgência (WHO.INT, 2020).

Dentre esses profissionais se encontram designers e makers que se uniram em diversas iniciativas ao redor do mundo para desenvolvimento e distribuição de EPI's para a comunidade médica atuando no combate à pandemia. $\mathrm{O}$ designer se apresenta como um profissional que pode atuar em diversas frentes, incluindo a solução de problemas sociais como é o caso do isolamento social.

Além da própria especificidade do saber de design, as ferramentas comumente utilizadas por makers, como impressoras $3 \mathrm{~d}$ e cortadoras a laser, devido à sua agilidade para produção customizada de artefatos, tem sido um grande auxiliar nesse processo produtivo emergencial.

Tanto as produções de designers quanto alguns makers, via de regra, se pautam em seus corolários de valores pelo objetivo de desenvolver artefatos para o auxílio da comunidade, das pessoas no sentido coletivo; o que, entretanto, não se pode afirmar para todos os empreendimento produtivos, sejam ou não industriais. A exemplo deste fato, encontramos na nossa busca via documentos eletrônicos registros de objetivos consideravelmente distintos entre iniciativas de projetos para corporações comerciais e entre indústrias, que registram a prioridade de obtenção de lucros, e não o atendimento das urgências do coletivo, das pessoas socioeconomicamente vulneráveis ou da minimização do quadro de desespero causado pela pandemia.

Nesse tempo de distanciamento social, muitos estabelecimentos comerciais têm sofrido uma crise econômica por não poderem receber seus clientes e causar aglomerações que vão contra as regras de distanciamento estabelecidas pela Organização Mundial da Saúde. Os estabelecimentos gastronômicos têm se inquietado para promover e adaptar a volta de seus clientes, sejam aos restaurantes de luxo ou aos mais populares, razão que justifica a importância de se projetar artefatos para além das máscaras e Face Shields.

Essa inquietação levou alguns empresários a pensarem soluções para que seus clientes possam utilizar seus serviços com menos riscos. Um exemplo disso é o restaurante Mediamatic ETEN de Amsterdã, especializado em comida vegana, que adotou cápsulas para suas mesas de modo a isolá-las para diminuir a interação física entre as pessoas no estabelecimento. As cápsulas de vidro, que lembram casas, foram instaladas em um deck na área externa do estabelecimento e abrigam duas ou três pessoas em uma mesa (Figura 01).

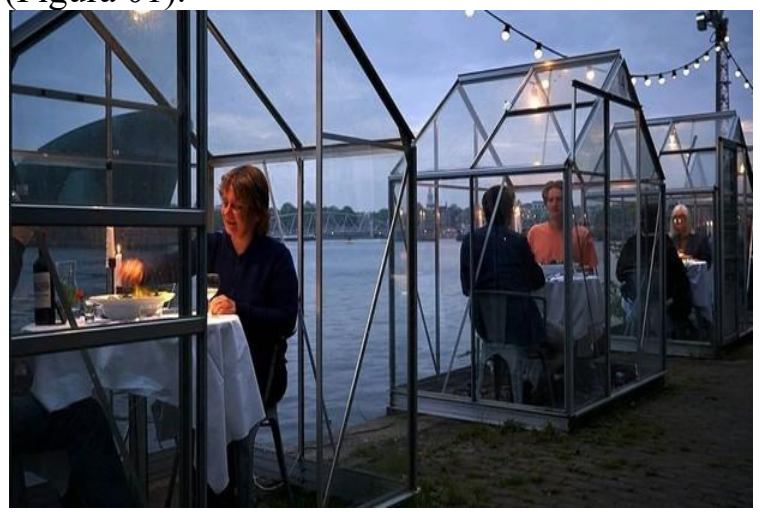

Figura 01: Cápsulas de isolamento do restaurante Mediamatic ETEN, na Holanda. Fonte: Site Mediamatic 
Um exemplo que contrasta com a sofisticação das "casinhas" à beira mar do Mediamatic é a solução encontrada pelo Fish Tales Bar \& Grill em Maryland que adotou boias infláveis individuais dotadas de um tampo de madeira sobre uma estrutura de suporte de metal dotada de rodinhas. $\mathrm{O}$ artefato permite que o usuário se movimente; porém, quanto se aproxima de outro cliente a boia garante que distanciamento físico seja mantido (Figura 02). O artefato é descrito por um dos donos como "uma versão adulta de um andador infantil".

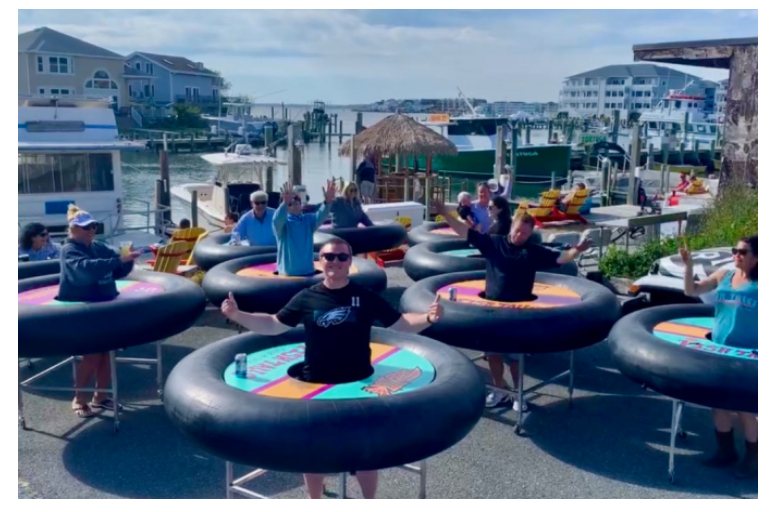

Figura 02: Mesas com boia do restaurante Fish Tales, em Maryland/EUA. Fonte: Site Viagem e Turismo Abril.

Sob o objetivo de atender a indivíduos, ou melhor, atender a certos indivíduos, são propostas algumas soluções que não valorizam o coletivo, mas, ao contrário, relegam a comunidade para segundo plano. Esses projetos representam duas diferentes tentativas das empresas no sentido de driblar as orientações científicas divulgadas pela OMS, que propõem que se "fique em casa" nos períodos críticos, e não que saiam em meio à pandemia para atividades não essenciais.

\section{0 valor de seguir cientistas, industriais, artífices e suas criações e práticas}

Para filósofo Bruno Latour, alguns princípios são necessários a quem queira compreender os fatos científicos e criações tecnológicas sem se deixar levar pelas seduções da crônica técnica: seguir os cientistas e demais atores sociais envolvidos na ação seria o primeiro e mais importante; isto sem se perder de vista o caminho, em geral tortuoso, que leva do fato (científico, ou de conhecimento) ao artefato. Outro aspecto fundamental seria perceber as incorporações de aliados humanos que tenham ou poderiam vir a ter interesse nos processos, aportando seus recursos materiais em favor de uma ideia, ou de um projeto. E um terceiro aspecto seria atentar aos fatores não humanos envolvidos - que segundo o autor, são protagonistas de certa agência, entretanto atendendo a interesses humanos - sem se desdenhar da influência das prerrogativas que aportam ou não, e das limitações que estes impõem à legitimação de um feito científico que se transforma em feito tecnológico - ou caixa preta.

Latour aponta também a demanda por legitimação dos processos e artefatos que têm lugar no "jogo da tecnociência", o qual decorre de modo diferente de um jogo do rúgbi, por exemplo, onde a bola permanece a mesma; o que não acontece na trajetória de um achado ou princípio científico, o qual se transforma através da busca dos atores humanos envolvidos por transformá-lo em técnica e tecnologia, enfim, em materialidade ou em prática. Justamente interessado na compreensão deste movimento é que o autor coloca a ideia de que o caminho percorrido pelos atores humanos e não humanos neste processo passa por diversas translações, sendo, portanto, movimentos de sentido, de valor econômico, e até de fins, objetivos e beneficiários a se atender. Aponta também que, curiosamente, as operações de sentido implicam frequentemente em atribuir quereres e benefícios de formas bastante arbitrárias, que autorizam afirmações do tipo 'se eu quero, você também quer', ou 'eu quero! porque você não quer?', ou ainda 'não haveria mal em se desviar um pouquinho' quanto ao objetivo central de um empreendimento. Atrás desses movimentos são realizadas intensas negociações, que geralmente levam ao remanejamento de interesses. 
Para fins de análise das propostas de artefatos oriundos dos Fab Labs apreciados nesta comunicação, assim como dos objetivos que movem seus artífices, serão instrumentalizados o conceito de caixa preta e as demais ideias teóricas e recomendações do autor acima sumarizadas.

\section{A cultura Maker e sua penetração no conceito de design}

Os makers como normalmente são conhecidos, são uma comunidade formada por indivíduos de diferentes vertentes que são considerados agentes de vanguarda na criação, experimentação, produção e distribuição de novas soluções tecnológicas, tornando-se assim líderes em inovação e que acabam afetando diversos setores como por exemplo a economia e a educação. Em função disso, são considerados sobretudo por suas características de colaboração e disseminação de ideias.

Makers, em uma definição mais abrangente, são pensadores que consertam, recriam ou montam objetos e sistemas de maneira criativa e inovadora. Essa comunidade teve mais reconhecimento durante os últimos anos devido a revistas e páginas relacionadas ao tema. Apesar de expressar uma tendência internacional, entretanto, enquanto denominação do movimento relativo a um estilo experimental e socialmente focado de produção que se vale de recursos tecnológicos da era digital, o maker surgiu primeiramente em contextos onde tais ferramentas primeiramente se popularizaram, haja visto que a massa de produções bibliográficas significativas sobre o tema seja de origem norte-americana.

Essa comunidade é composta de inventores, artesãos, hackers, empresários, artistas, cientistas, engenheiros, designers, professores ou ativistas, de quase todas as idades e origens. Segundo Nascimento e Pólvora (2018), é pelo ato do fazer que se consegue um melhor entendimento dos ambientes que habitamos e de como transformar os mesmos através das habilidades tecnológicas aprendidas, da inovação e da criação de artefatos.

O movimento maker se refere ao crescente número de pessoas que estão engajadas na produção criativa de artefatos no seu cotidiano e que encontram plataformas físicas e digitais para compartilhar seus processos e produtos com outros (Halverson; Sheridan, 2014, tradução dos autores).

Focado em "colocar as mãos na massa", nessa cultura é essencial o conhecimento que é originado no ato de desmontar coisas com a intenção de entender a maneira como elas funcionam; e desse ato, se conseguir criar novos e mais interessantes objetos.

O termo maker traduzido do inglês significa fazer, fazer esse que é tido por Halverson e Sheridan (2014) como parte da identidade humana, pois não importa onde estejamos ou qual sejam nossas metas, sempre estamos fazendo algo. Assim, o movimento maker é definido mais a partir das pessoas que fazem parte dele do que onde e como esse fazer acontece.

É necessário enfatizar a natureza democratizadora do movimento, que tenta produzir através de hardware mais acessível, promover o fácil acesso à fabricação digital e o compartilhamento de softwares e projetos. No centro de tudo está a crença de que para se criar é necessário acesso a ferramentas e informações diversas que se façam necessárias: a conexão com outros, a troca de ideias, o suporte das mais diversas formas online, além do contato com comunidades offline e eventos. $\mathrm{O}$ acesso a todos esses recursos oportuniza que qualquer um possa criar utilizando toda a tecnologia disponível.

O termo "open source" é um dos mais populares e adotados nos contextos maker (HALVERSON; SHERIDON, 2018) e a maioria dos projetos vindos de jovens ou adultos, amadores ou profissionais, digitais ou analógicos, acabam escolhendo e utilizando softwares ou hardwares FLOSS (Free/Libre/Open Source). Com esses recursos, os criadores se sentem livres para escolher as ferramentas que desejam utilizar e como aplicá-las e, o mais importante, livres para enquadrar e compartilhar suas criações sem maiores restrições.

É através dessas plataformas de colaboração, através da internet e espaços físicos, que esse processo de criação, modificação, duplicação de objetos e sistemas pode ser realizado em diversos lugares, como residências, garagens, escolas, empresas, museus, livrarias, makerspaces, hackerspaces, 
Fab Labs ou outros ambientes voltados para a inovação, conhecidos como ambientes ou espaços maker ou pelo termo makerspaces.

Classificados por Silva e Souza (2020) como oficinas compartilhadas que tem como função unir o conhecimento com a tecnologia, esses locais tornam possível tanto para amadores como para profissionais colocarem as mãos na massa, pois eles são equipados com tecnologias de fabricação digital e inovação aberta. Eles possuem equipamentos de manufatura aditiva (impressão 3D) e de corte, marcação ou desbaste (Fresadoras, CNC ou máquinas a laser), que possibilitam a execução de uma vasta gama de projetos.

Cada um destes espaços independentes possui regras, serviços e logística própria. As tipologias de ambientes maker se diferenciam em função de suas propostas. Entretanto, Fab Labs são makerspaces que possuem regras de funcionamento, principalmente de equipamento básico para sua operação, gestão e abertura ao público, em conformidade com as propostas do MIT e de sua rede global (SILVA; SOUZA, 2020).

Os espaços oferecem um ambiente flexível e criativo que ajuda na inovação e permitem que os participantes consigam trabalhar em uma intersecção entre o digital e o físico, fazendo uso das ferramentas digitais disponíveis para desenvolver soluções para problemas reais que possam ser confeccionados utilizando as ferramentas de fabricação digital. Segundo Silva e Souza (2020), para além da inovação, esses espaços funcionam como ferramentas para o empreendedorismo, já que demandam o desenvolvimento de competências para a realização de negócios: a aprendizagem, a invenção e a inovação. Dadas as características dos espaços e da cultura maker, tais como descritos pelo autor, entre outras não mencionadas, como a busca de soluções inovadoras e artesanais para desafios que emergem, é possível afirmar que a ideias advindas do movimento maker tem funcionado como um forte vetor de transformação das práticas e mesmo do resgate de orientações teóricas que foram relativamente ofuscadas, no campo das atuações concretas do design. Entre ela, o objetivo de atender a demandas de coletivos.

\section{Criação e desenvolvimento dos Fab Labs}

Existem diversas iniciativas e comunidades makers ao redor do globo, mas a principal como mostra Nascimento e Pólvora (2018) surgiu em 2005 no Instituto de Tecnologia de Massachusetts (MIT) no Centro para Bits e Átomos (CBA) como uma ferramenta pedagógica, proposta do professor Neil Gershenfeld para auxiliar pessoas comuns a solucionarem seus próprios problemas. Essa ferramenta foi denominada Fab Labs (fabrication laboratories - laboratórios de fabricação). Atualmente eles são o melhor exemplo de makerspace e através da Fab Lab Foundation se disseminaram em diversos pontos ao redor do mundo, incluindo o Brasil.

De acordo com a Fab Foundation, um Fab Lab é uma plataforma de prototipagem rápida utilizada para educação, inovação e expressão pessoal. É um lugar para brincar, criar, um lugar destinado para o aprendizado e a inovação. Esse ambiente proporciona aos usuários contato com habilidades, materiais e tecnologia avançada, tornando possível para qualquer pessoa em qualquer lugar, criar (quase) tudo.

Os laboratórios funcionam simultaneamente como uma rede de manufatura, campus educacional e laboratório de pesquisa, atuando de modo a proporcionar o desenvolvimento de um novo método de produção e fabricação pessoal. Trata-se do modelo idealizado de uma comunidade aberta composta de fabricadores, artistas, cientistas, engenheiros, estudantes, amadores e profissionais em mais de 100 países e, aproximadamente, 1750 unidades ao redor do mundo. Eles funcionam, junto com algumas outras iniciativas, para a popularização da fabricação digital, proporcionando maior acesso ao conhecimento e manuseio concreto dessas tecnologias.

O ecossistema inovador dos laboratórios consiste em uma rede de parceiros com os quais os usuários podem interagir e trocar experiências e conhecimentos. A principal missão do laboratório é fazer com que os usuários utilizem as tecnologias para projetar e criar a nova geração de ferramentas das quais eles precisam (MIKHAK et al, 2002).

A administração geral dos Fab Labs é feita por meio de uma associação, fundação, universidade ou programa governamental (OLIVEIRA, 2014); assim eles são categorizados de acordo 
com o seu conselho administrativo em Fab Labs Acadêmicos, Fab Labs Profissionais e Fab Labs Públicos. De acordo com a Fab Foundation, são necessários quatro requerimentos básicos para receber a nomenclatura oficial de Fab Lab, sendo eles: acesso do público ao ambiente, estar inscrito no Fab Charter; possuir processos e ferramentas de prototipagem específicos para que qualquer projeto executado em uma unidade possa ser executado facilmente em outra; e participar da comunidade global do Fab Lab.

\section{A rede de colaboração criada para a pandemia}

A pandemia da COVID-19 ocasionou uma demanda não-planejada por equipamentos de proteção individual - EPI's para médicos, enfermeiros e todos os profissionais que estão trabalhando na linha de frente do combate à essa doença, bem como outros artefatos como respiradores mecânicos e válvulas Venturi - válvula que se conecta à máscara facial do paciente para fornecer oxigênio e que precisa ser trocada a cada oito horas para garantir seu uso correto (ESTADÃO, 2020). Para suprir essa grande demanda por EPI'S, designers de todo o mundo têm se mobilizado para ajudar na produção emergencial trabalhando no projeto, fabricação e distribuição desses artefatos. Os profissionais que trabalham com máquinas de impressão 3D estão ajudando na confecção, principalmente, de máscaras de proteção do tipo Face Shield que estão sendo doadas aos profissionais mais expostos ao contágio.

Além dos designers, a rede de colaboração criada no movimento maker inclui voluntários dos mais diversos âmbitos, podendo ajudar na produção dos artefatos qualquer pessoa que tenha uma impressora 3D. Ainda assim, mesmo que não se tenha uma máquina como essa, existem outras formas de contribuir com essas campanhas. Protótipos de respiradores mecânicos, válvulas de Venturi, máscaras Face Shields e outros artefatos têm sido produzidos através da fabricação digital para responder à demanda causada pela pandemia que vem crescendo mais rápido do que a indústria pode suprir. Através do compartilhamento de projetos com "código aberto" tem sido possível espalhar a fabricação de protetores por um território ilimitado. O código aberto permite que um projeto seja compartilhado com arquivos editáveis para ajustes e melhorias, o que gera uma rede de colaboração entre projetistas e voluntários.

Nas campanhas articuladas pelo movimento maker não é necessário possuir um equipamento de tecnologia avançada para ajudar. A impressão 3D de cada viseira de proteção do tipo Face Shield custa em torno de $\mathrm{R} \$ 22,00$, o que impulsionou a criação de outras frentes de apoio para ajudar no custeio desse material, por exemplo, através de doação em dinheiro ou matéria-prima para a impressão 3D (NETV, 2020).

\subsection{Projeto Cada Impressão Conta e Projeto Hígia}

A campanha Cada Impressão Conta, liderada pela e-NABLE Brasil, busca alternativas para ajudar, além dos profissionais da saúde, todos aqueles que precisam estar nas ruas em meio a pandemia, como colaboradores de limpeza, segurança pública, infraestrutura, entre outros, através da busca por soluções colaborativas e sustentáveis para a crise. O projeto Cada Impressão Conta tem contribuído prototipando, testando e produzindo máscaras de proteção do tipo Face Shield que são doadas para instituições de saúde (Figuras 03 e 04). O projeto começou na Bahia, porém, logo ganhou uma adesão significativa de colaboradores pelo Brasil, com destaque para em Pernambuco (NETV, 2020). Participam do Movimento Cada Impressão Conta Pernambuco as seguintes instituições/empresas: Rede E-nable Brasil, Anbiotec, ITCBIO, Lab Griô, IP.rec, Porto Digital, Fab Lab Recife, Casa Criatura, Coletivo 3D, Secti-PE, Parqtel, Senfio, Orbe Lab, Idea PD, Recrie3D, Void3D, FabPro Engenharia e Impressão 3D PE, UNICAP-ICAM, Armazém da Criatividade, Secretaria do Meio Ambiente e Secretaria de Saúde do Estado de Pernambuco.

A logística da iniciativa, que funciona com a colaboração de diversas entidades além da sociedade civil, se organiza através de um mapeamento de demanda por protetores a partir do contato direto com profissionais e instituições de saúde (e-NABLE, 2020). A partir desse mapeamento, instituições públicas e privadas são escolhidas para funcionar como postos de arrecadação de doações. Nesses locais são definidos quais destinos o material doado tomará e, assim, é realizada a produção e 
distribuição dos artefatos, levando-se em conta a ordem de chegada das demandas, a quantidade de leitos de UTI - Unidade de Tratamento Intensivo e a necessidade de cada instituição (e-NABLE, 2020).

A e-NABLE Brasil, organizadora do projeto Cada Impressão Conta, trabalha com uma rede de voluntários que produzem, projetam, imprimem e distribuem próteses feitas em impressoras 3D para crianças e adultos com deficiência em membros superiores (e-NABLE, 2020). Desde o início da atuação da campanha em março de 2020, até maio de 2020 já haviam sido distribuídos mais de 28.000 protetores faciais ajudando 80 instituições de saúde e serviços públicos essenciais de Pernambuco.

A decisão da entidade em se dedicar emergencialmente à produção deste artefato pode ser compreendida no contexto das translações e remanejamento de objetivos apontado por Latour, caracterizando-se neste caso como uma translação onde o tipo de deslocamento não descaracteriza o fundamento primeiro do grupo produtor, originalmente também devotado a causas sociais.

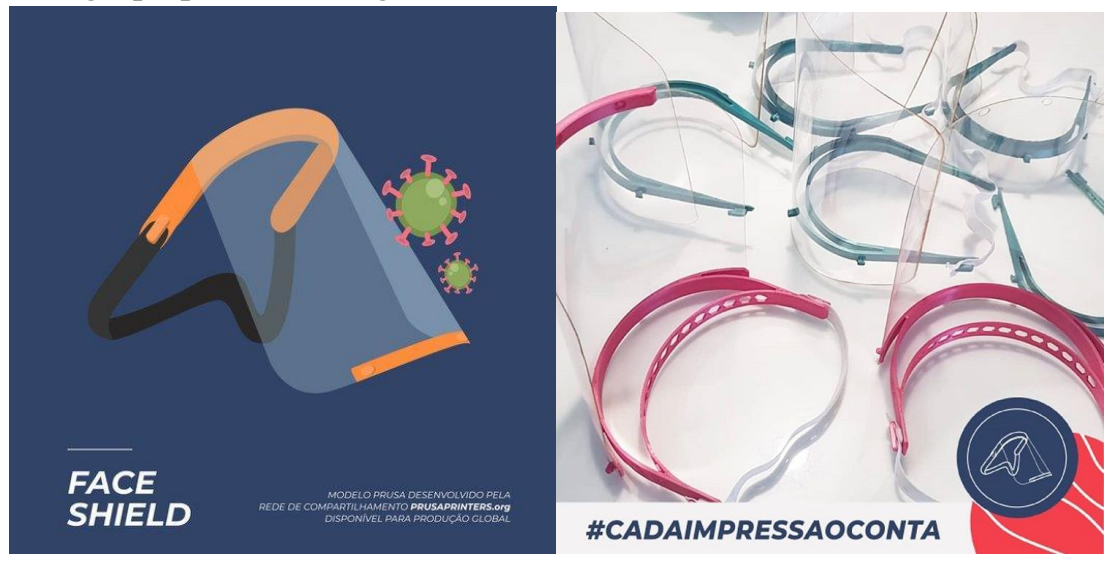

Figuras 03 e 04: Material de divulgação da campanha Cada Impressão Conta para a produção de máscaras de proteção Face Shield. Fonte: Instagram Cada Impressão Conta

A máscara Face Shield produzida por essa campanha, PRUSA RC2, é um projeto que foi desenvolvido na República Tcheca. É composta por uma viseira protetora feita de folha de acetato ou PETG - Polietileno Tereftalato de Etileno Glicol (material similar ao PET, bastante versátil) cortada à laser, fixada com um suporte produzido pela impressão 3D. Por utilizar um processo de adição de matéria na fabricação digital, essa máscara se torna um pouco demorada na sua produção e montagem se comparada aos processos que utilizam apenas a subtração como corte à laser.

Visando aumentar a produtividade e otimizar tempo para conseguir ajudar mais pessoas nessa pandemia algumas melhorias de projeto de EPI's já têm sido postas em prática. O designer de produtos Jake Rynkiewicz, de Chicago (EUA), criou o modelo Origami Shield que tem sido amplamente utilizado por profissionais de saúde no mundo inteiro. A máscara Origami Shield é fabricada a partir de um único material, o acetato, o que facilita sua produção por utilizar apenas um método de fabricação digital: o corte à laser (Figura 05).



Figura 05: Máscara de proteção Origami Shield. Fonte: Design Concentric. 


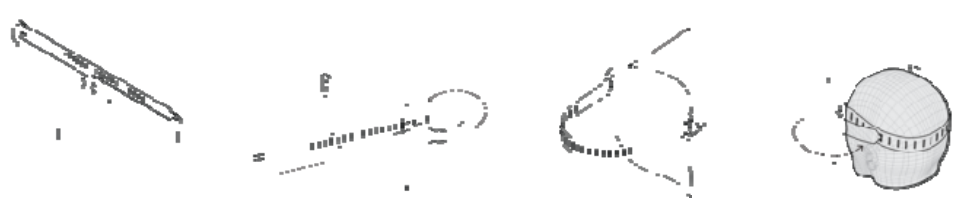

Figura 06: Montagem da máscara Origami Shield. Fonte: Design Concentric.

Além disso, sua forma plana facilita a distribuição por só precisar ser montada (através de dobraduras) quando for utilizada (Figura 06). Os profissionais da rede Fab Lab Recife estiveram em contato direto com o criador da Origami Shield, criando uma colaboração na projeção de melhorias e aprimoramento do artefato. Até o mês de maio de 2020, o movimento Cada Impressão Conta de Pernambuco já tinha distribuído mais de 5.200 unidades da Origami Shield.

Outra iniciativa de produção e distribuição de EPI's para o combate à pandemia é o Projeto Hígia. Desenvolvido por de um grupo voluntário, o projeto Hígia é uma iniciativa nacional voltada para a produção de uma proteção individual por meio de impressoras $3 \mathrm{D}$, para ser utilizada por médicos, dentistas e outros profissionais da área da saúde pública envolvidos com o atendimento às pessoas suspeitas de terem sido infectadas, ou comprovadamente portadoras do novo coronavírus, vítimas da Covid-19 (PROJETO HIGIA, 2020).

A iniciativa em Pernambuco é coordenada pelo Laboratório Grea3D (Grupo de experimentação em artefatos 3D) que está vinculado ao Departamento de Expressão Gráfica do Centro de Artes e Comunicação (CAC) da UFPE (ASCOM, 2020). A atuação do laboratório foi na produção de face shields que foram distribuídos junto a hospitais da região de Recife.

$\mathrm{O}$ projeto conseguiu colaborar com a entrega nacional de cerca de 10 mil protetores atendendo quase 50 instituições em diversos municípios do estado de Pernambuco. As máscaras produzidas no estado foram feitas por meio de impressão 3D a partir de um modelo definido pelo Projeto Hígia Nacional e foram distribuídas principalmente na Região Metropolitana de Recife.

\subsection{Projeto Lava Mão}

Com o processo de flexibilização do distanciamento social que ocorre no Recife, a população tem voltado gradativamente às ruas e, com isso, a relação com os espaços públicos se modificou tornandose mais complexa e desafiadora no pós pandemia. Tendo em vista esse novo contexto de convívio em sociedade os projetos do Fab Lab Recife entraram em uma nova fase, como parte do programa Fab City Recife, programa que integra a iniciativa global Fab City que pretende trazer para 34 cidades um modelo urbano autossustentável até 2054.

Focando na higienização das pessoas durante esse retorno, o projeto desenvolvido pelo arquiteto Peu Carneiro/Fab Lab Recife tem por objetivo implementar artefatos que promovam uma nova relação entre pessoa-espaço público exigida para o novo estilo de vida pós-pandemia. Nessa nova fase de enfrentamento, é importante pensar na volta das pessoas ao espaço público e rotinas interrompidas pela Covid-19. Assim foi desenvolvido pelo o Fab Lab Recife, em parceria com a ConcrEpoxi Artefatos e a Prefeitura Recife por intermédio da Secretaria Executiva de Inovação Urbana, o Lava-Mão, apresentado na figura 07. (FAB LAB RECIFE, 2020). 


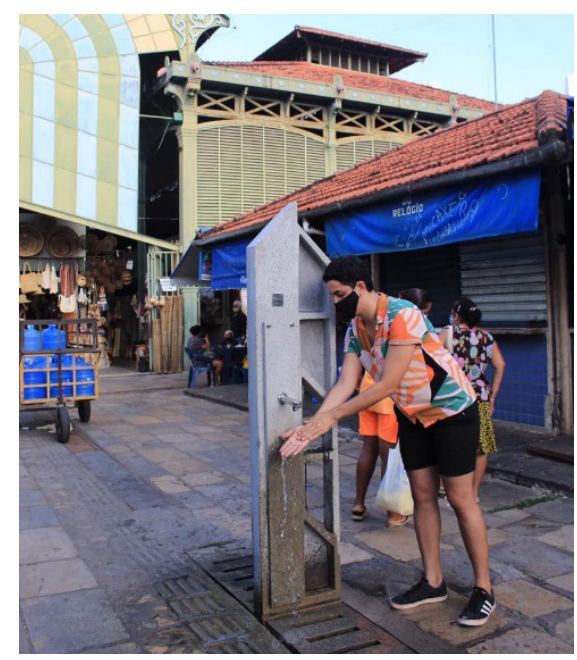

Figura 07: Pia pública em estrutura pré moldada em blocos de concreto implementada no Mercado de São José, Recife. Fonte: Acervo pessoal.

$\mathrm{O}$ artefato consiste em uma pia pré-moldada com blocos de concreto onde foram instaladas duas torneiras com mecanismos de controle temporal, acompanhado por painéis informativos com instruções sobre a maneira correta de higienizar as mãos (FAB LAB RECIFE, 2020). O protótipo inicial possui um design moderno e geométrico que lembra as antigas bicas existentes na cidade durante os anos 20. Ele foi instalado na região central da cidade no Mercado de São José, local onde existe uma grande circulação de pessoas, e o próximo ponto a ser beneficiado com o Lava-Mão será a praça do Derby, ponto estratégico onde existe a convergência de linhas de transporte público.

Para a materialização da ideia levada com o projeto Lava Mão, um novo exemplo de arregimentação de aliados e translação no sentido de alternância quantos aos recursos materiais empregados no empreendimento é verificada. Novamente o que se pode destacar é o fato de que permanece no contexto deste projeto uma característica que é recorrente aos demais levados por estruturas que partilham do ideário de atendimento do social que é próprio do movimento maker, ao mesmo tempo que contou, entre seus interlocutores e apoiadores, com recursos humanos e financeiros oriundos do universo universitário e estatal; ou seja, valeu-se da parceria com instituições que somaram recursos, além de acrescentarem legitimidade e garantia da dimensão coletiva do projeto.

\section{Considerações Finais}

No contexto das produções que objetivamos neste trabalho, voltado à materialização de artefatos emergenciais para o combate à propagação do coronavírus e da mitigação das consequências humanas e sociais negativas da pandemia, tomadas sobre a ótica das contribuições teóricas de Bruno Latour, podemos interpretar como fatores não humanos o próprio vírus, o projetos de artefatos pré-existentes, dos quais as comunidades maker lançam mãos em suas propostas, e as próprias engrenagens econômicas e produtivas tradicionais, para as quais a produção em tela representa uma iniciativa contracultural.

Destacamos que é esta mesma economia que, se por um lado engendra a recusa da posição de proteger o ser humano (sobretudo os socialmente mais vulneráveis) por parte de alguns agentes econômicos hegemônicos, que preferem reabrir o comércio e escolas ainda que não haja vacinas disponíveis, numa tentativa de abstrair a grave situação social e as mudanças que esta exige; por outro, faz chegar aos atores sociais interessados em uma produção socialmente responsável e eticamente fundamentada, ferramentas tecnológicas que podem auxiliar na transformação social. A esse respeito, a pandemia também tornou mais transparente as alianças buscadas pelos interessados nas causas sociais coletivas, a exemplo das iniciativas de produção de Face Shields e outros implementos para fins hospitalares em Pernambuco, que associaram designers, makers, laboratórios e associações classistas universitários e o poder público, a partir da inserção de certos gestores (das IFES, do Estado e de alguns municípios) que, no cenário atual da política brasileira, assumiram a postura de desafiar o 
poder governamental maior e se aliaram às posições comprometidas com o bem estar de suas comunidades.

Por outro lado, no trabalho de busca mais geral por artefatos que visavam auxiliar a sociedade no combate à pandemia, nos deparamos com projetos que se voltaram aos interesses de uma minoria que não deseja abdicar de seus costumes de socialidade de burguesia antiga, como ir a restaurantes, hospedagens em hotéis de luxo e a continuarem a fazer suas viagens de turismo, entre outras razões que em tese justificam a posição de se projetar certos artefatos que relegam a comunidade ao segundo plano. Sob o objetivo supostamente humanista de atender às subjetividades humanas, opta-se por atender primeiramente aos indivíduos, ou melhor, certos indivíduos cujas condições no espaço social lhes permitem desfrutar de sua individualidade.

Em síntese, concluímos que dentre as iniciativas identificadas na pesquisa, algumas, numericamente minoritárias, expressaram preocupação e senso de responsabilidade para com o outro, o coletivo e a problemática ambiental, não ignorando a premência das necessidades e desigualdades sociais específicas no contexto pesquisado; enquanto outras seguiram na perspectiva do individualismo. Como expressões do atendimento às demanda de cunho mercadológico, indiferentes às necessidades de transformação mais profundas das práticas de consumo e estilo de vida no mundo pós-pandemia, às quais dizem respeito à atividade do design, esses projetos expressaram o apego às antigas práticas de desdém para com o outro e o meio ambiente recorrentes em nossa sociedade, o que compreendemos com uma espécie de miopia só passível de cura a partir de longo processo cultural que envolva a educação.

Para finalizar, acrescentamos que a pouca representatividade numérica dos projetos que expressam a transformação nos valores do design cotejados nas iniciativas pesquisadas não expressa, a nosso ver, algo sem importância, já que a partir do ponto de vista canônico que fundamenta a atividade, sempre haverá valor no atendimento das demandas sociais, o valor do outro em suas necessidades coletivas, o que nos faz intuir que essas produções, ou as experiências adquiridas com elas, podem se tornar muito úteis no contexto de pós-pandemia.

\section{Designers from the maker movement in the fight against the COVID-19: analysis of the initiatives carried out in Pernambuco}

Abstract: The new coronavirus pandemic has had a major impact in several areas of the industry. One of the most affected was the sector responsible for the manufacture and distribution of PPE's, essential elements to reduce the spread of the virus. This paper addresses the productions of designers and activists, who work in collaboration with entities associated with the ideas of the maker movement. As a theoretical analysis tool, the concepts of black box and human and non-human factors were used in the transformation of scientific ideas into materiality, as well as Latour's reflections on regrouping allies and reallocating interests in technological production. Internet records related to the performance of digital manufacturing laboratories in the production of these essential items in the fight against the virus served as an empirical object. From the analysis we concluded that the proposals that turned to a collective and inclusive perspective, were the result of interests formed in collaborative processes.

Keywords: Maker Movement; Design; Digital Fabrication; COVID-19 


\section{Referências bibliográficas}

About the Fab Foundation. Fab Foundation, 2020. Disponível em <https://fabfoundation.org/about/>. Acesso em: 13 Ago. 2020.

Ascom. Projeto Hígia PE distribui 5,5 mil protetores faciais para municípios pernambucanos. UFPE, 2020. Disponível em: <https://www.ufpe.br/covid-19/ascom/-

/asset_publisher/hdBGtsdgB5Ee/content/projeto-higia-pe-distribui-5-5-mil-protetores-faciais-paramunicipios-pernambucanos/40615>. Acesso em: 13 Ago. 2020.

CAMPANHA Cada Impressão Conta. NETV, 2020. Disponível em:

<https://drive.google.com/file/d/1BI6F13HFvK1tet5djBXMLYldM2czTXZb/view>. Acesso em: 12 Ago. 2020.

COVID-19: Impressoras 3D fabricam equipamentos de respiração na Itália. Estadão Summit Saúde, 2020. Disponível em: <https://summitsaude.estadao.com.br/covid-19-impressoras-3d-fabricamequipamentos-de-respiracao-na-italia/>. Acesso em: 13 Ago. 2020.

CADA Impressão Conta Pernambuco. Apoia-se, 2020. Disponível em: <https://apoia.se/cadaimpressaoconta>. Acesso em: 13 de Ago. 2020.

CADA Impressão Conta. e-NABLE, 2020. Disponível em: <http://enablebrasil.org/wp/cadaimpressaoconta/>. Acesso em: 10 de Ago. 2020.

DANTAS, Carolina. Covid-19 se espalhou pelo mundo mais devagar do que o H1N1 aponta levantamento. G1, 2020. Disponível em:

<https://g1.globo.com/bemestar/coronavirus/noticia/2020/03/04/covid-19-se-espalhou-pelo-mundomais-devagar-do-que-o-h1n1-aponta-levantamento.ghtml>. Acesso em: 10 Ago. 2020.

Origami_shield. Design Concentric, 2020. Disponível em: <http://www.designconcentric.com/origamishield>. Acesso em: 14 Ago. 2020.

HALVERSON E. R.; SHERIDAN K. M. The Maker Movement in Education. Havard Educacional Review, v. 84, n. 4. p. 495-504, 2014.

LAVA-MÃO: CRIANDO ARTEFATOS PARA UMA NOVA RELAÇÃO COM O ESPAÇO PÚBLICO. Fab Lab Recife, 2020. Disponível em: <https://www.fablabrecife.com/lava-mao-criando-artefatos-para-umanova-relacao-com-o-espaco-publico/>. Acesso em 13 Ago. 2020.

LATOUR, Bruno. Ciência em ação: como seguir cientistas e engenheiros sociedade afora/Bruno Latour: tradução de Ivone C. Benedetti; revisão de tradução Jesus de Paula Assis. - SaoPaulo. Editora UNESp, 2000.

LIGERO, Bárbara. Soluções hilárias para manter o distanciamento em restaurantes. Viagem e Turismo Abril. Disponível em: <https://viagemeturismo.abril.com.br/materias/solucoes-hilarias-para-manter-odistanciamento-em-restaurantes/>. Acesso em: 14 Ago. 2020.

LÖBACH, Berndt. Design Industrial. Editora Edgard Blücher Ltda. São Paulo, 2001.

MIKHAK, Bakhtiar et al. Fab Lab: an alternate model of ICT for development. In: 2nd international conference on open collaborative design for sustainable innovation. 2002.

MARTIN, L. The promise of the maker movement for education. Journal of Pre-College Engineering Education Research (J-PEER), v. 5, n. 1, p. 30-39, 2015.

MUNARI, Bruno. Das Coisas Nascem Coisas. Martins Fontes, São Paulo., 1971

NASCIMENTO, Susana; PÓLVORA, Alexandre. Maker cultures and the prospects for technological action. Science and engineering ethics, v. 24, n. 3, p. 927-946, 2018.

NEGRI, F.; ZUCOLOTO, G.; MIRANDA, P.; KOELLER, P. Ciência e tecnologia frente à pandemia. Centro de pesquisa em Ciência, Tecnologia e Sociedade. Mar. 2020. Disponível em: <https://www.ipea.gov.br/cts/pt/central-de-conteudo/artigos/artigos/182-corona\#_edn1>. Acesso em: 10 Ago. 2020. 
OLIVEIRA, Diego Jucá de Lima. O uso da prototipagem e fabricação digital no ambiente FAB LAB. 2016.

Painel de casos de doença pelo CORONAVIRUS 2019 (COVID-19) no Brasil. Ministério da Saúde, 2020. Disponível em: <https://covid.saude.gov.br/> Acesso em: 10 Ago. 2020.

Projeto Hígia, protetores faciais por impressão 3D para hospitais em combate à COVID-19, 2020. Disponível em: <https://www.projetohigia.com.br/>. Acesso em: 13 de Ago. 2020.

R\&D Blueprint and COVID-19. OMS, 2020. Disponível em:

<https://www.who.int/teams/blueprint/covid-19>. Acesso em: 10 Ago. 2020.

SILVA, L.; SOUZA, R. Ambiente Maker e sua cultura. Revista VIA. Santa Catarina, v. 8. p. 5-14. Mar., 2020.

SOBRE a doença. Ministério da Saúde, 2020. Disponível em: <https://coronavirus.saude.gov.br/sobrea-doenca>. Acesso em: 12 Ago. 2020.

WERNECK, Guilherme Loureiro ; CARVALHO, Marília Sá . A pandemia de COVID-19 no Brasil: crônica de uma crise sanitária anunciada. Cad. Saúde Pública, Rio de Janeiro, v. 36, n. 5, e00068820, Abr. 2020. Disponível em: http://cadernos.ensp.fiocruz.br/csp/artigo/1036/a-pandemia-de-covid-19no-brasil-cronica-de-uma-crise-sanitaria-anunciada. Acesso em 10 Ago. 2020.

http://dx.doi.org/10.1590/0102-311X00068820. 